\title{
MERCADERES, PRODUCTOS Y EMBARCACIONES, EN LAS RELACIONES COMERCIALES MARÍTIMAS ENTRE DOS CIUDADES MEDITERRANEAS: ORÁN - VALENCIA (1600-1703)
}

\author{
Roberto BLANES ANDRÉS
}

Recibido: $28 / 06 / 2012$

Aceptado: 11/10/2012

\begin{abstract}
RESUMEN: Este trabajo nos introduce en lo que debió ser el comercio marítimo exportador oraní destinado a Valencia a lo largo del seiscientos y los tres primeros años del setecientos (1600-1703); teniendo como base documental la Serie Petge de Mar (perteneciente a la sección Maestre Racional; custodiada en el Archivo del Reino de Valencia), pudiendo conjeturar con relativa sencillez particularidades y asuntos heterogéneos de la actividad mercantil que se construyó entre ambas ciudades; Orán como remitente de productos de diversa índole y, Valencia, como destinataria y consumidora de ellos. Un mundo visto desde el observatorio que es el puerto-playa del Grao de Valencia, donde, a modo de calidoscopio, nos pondrá en contacto con un universo formado por diferentes modelos de embarcaciones y los patrones que las dirigían; artículos (tan importantes en este comercio como el trigo, los esclavos, las pieles o la cera) o a los hombres vinculados en este intercambio mercantil, tanto desde la vertiente exportadora como importadora; teniendo, siempre, como testigo el mar Mediterráneo.
\end{abstract}

PALABRAS CLAVE: Exportación, Comercio Marítimo, Productos, Mercaderes.

ABSTRACT: This paper introduces us to what must have been the Oran's export and maritime trade to Valencia over the seventeenth century and the first three years of the eighteenth century (1600-1703), on the basis of the documentary series Peatge the Mar. These series belong to the section of Maestre Racional and are preserved in the Archives of the Kingdom of Valencia,and surmise with relative simplicity the particularities and heterogeneous issues of the market activity that was taking place between two cities, Oran as the sender of products of various kinds, and Valencia, as the receiver and consumer of them. A world seen from the port-beach of Valencia (El Grao), where, like a kaleidosope, we will have contaskippers, products (such as wheat, slaves, skins and wax), or the men linked in this commerce exchange from both the export and import sides, always having the Mediterranean Sea as a witness.

KEYWORDS: Export, Maritime Trade, Products, Merchants.

Se puede afirmar que las relaciones entre las dos orillas del Mediterráneo durante la Edad Moderna fueron conflictivas, pero como también lo fueron entre el 
Mediterráneo hispánico y el francés por citar sólo un ejemplo. Es cierto que en la frontera entre ambos bordes del mar se levantaba el muro de la separación religiosa, pero este muro distó mucho de ser impermeable. Es cierto que ya desde el siglo XVI se había promulgado un sinfín de pragmáticas y ordenaciones vetando el comercio, e incluso el mero contacto con los puertos "de allende", pero la misma repetición de las prohibiciones nos indica la futilidad de las mismas. Y lo mismo ocurriría en la centuria siguiente cuando, a pesar de la situación conflictiva entre ambas partes, hispana y norteafricana, tanto bélica como religiosa, fue incapaz de paralizar totalmente los intercambios mercantiles. Y esto lo fue, sobre todo, porque, ambas partes se complementaban, es decir cada una de ellas poseía lo que a la otra le faltaba ${ }^{1}$. Es por ello que, en el presente trabajo pretendemos mostrar cómo, a pesar de las disposiciones oficiales, las relaciones entre dos ciudades consideradas oficialmente enemigas, Orán y Valencia, fueron relativamente fluidas a lo largo del siglo XVII. Asimismo, observaremos cómo el único motivo serio y efectivo capaz de interrumpir estos vínculos comerciales fue el sanitario.

En efecto, la única crisis que hacía que el comercio se suspendiese y se derivase temporalmente hacia otros lugares eran las enfermedades infectocontagiosas, verdadero azote demográfico que activaba todas las alarmas protectoras cuando se tenía información de algún foco. Los puertos norteafricanos del Mediterráneo occidental, por desgracia, sufrieron diferentes pestes, que no sólo mermaron la población, sino que suspendieron el comercio oriundo de estos lugares; obligando a las ciudades receptoras a tomar medidas preventivas con todas las embarcaciones, productos y personas procedentes de este litoral.

\section{ASPECTOS GENERALES DEL COMERCIO ENTRE ESPAÑA Y EL MAGREB EN LA EDAD MODERNA.}

Ya Ferdinand Braudel había advertido de cómo la importancia comercial del ámbito mediterráneo decrecía en favor de las relaciones mercantiles que se establecieron entre ambas orillas del Atlántico. En este contexto, los países del Islam, bañados por el Mediterráneo, interpretaban en el siglo XVII un papel subsidiario en el comercio, aunque no por ello desdeñable. Desplegaban una doble función, tanto la relacionada con el corso como el franco comercio con Francia o Italia. Ahora bien, la primera actividad, la pirática suponía un verdadero hándicap para el comercio marítimo hispano. Sobre esta cuestión recordemos que, desde el

${ }^{1}$ Martín CORRALES, E. (2008). «Exportaciones españolas al Mediterráneo musulmán (siglos XVI-XVIII)», en Circulación de personas e intercambios comerciales en el Mediterráneo y en el Atlántico (siglos XVI, XVII, XVIII), dirigido por José Antonio MARTínEZ TorRES, monografías, 32, C. S. I. C., Madrid, pp. 192-193. 
fracaso de la toma de Argel por Carlos V, la monarquía hispana ya no volverá a tomar la iniciativa en este campo. Es más, se renunciará a la puesta en funcionamiento de un sistema defensivo de galeras, tan solicitado por las Cortes, tanto valencianas como catalanas, para pasar a un sistema de defensa pasivo sustanciado en una red de baluartes. Esta última opción, la de basar la protección de las costas en un sistema de bastiones, se tomó, sobre todo, porque precisaba un menor costo para la corona, siempre tan escasa de recursos -el Mediterráneo hispano se consideró secundario respecto a los intereses de la monarquía, más interesado en los asuntos de Italia y de los Países Bajos. Esta política defensiva estática tuvo una consecuencia clara: la iniciativa bélica marítima en el Mediterránea occidental estuvo casi siempre en manos de los corsarios argelinos. Ahora bien, la existencia de los presidios españoles en el litoral norteafricano posibilitaba el comercio con las modestas economías magrebíes y, en este intercambio comercial, tendrían un papel preponderante los judíos sefarditas afincados en la zona. ${ }^{2}$ La conquista de los enclaves africanos había suscitado el preámbulo de nuevos recorridos comerciales, en mercados donde la representación especulativa castellana era casi inexistente, rutas que no tardarían en ser utilizadas por hombres de negocios del levante español.

Es cierto que la existencia de relaciones comerciales entre el Mediterráneo español y el magrebí no resulta una novedad histórica ${ }^{3}$, pero cabe abordarlas desde una perspectiva global que posibilite el conocimiento de todas aquellas áreas que se vieron afectadas por este tráfico comercial ${ }^{4}$. Es por ello que acercarnos al comercio que se desarrolló desde Orán es también estudiar el de la propia ciudad de Valencia como extremo mercantil y, cómo no, de su burguesía mercantil.

\section{LA IMPORTANCIA DE ORÁN EN EL COMERCIO ENTRE VALENCIA Y EL NORTE DE ÁFRICA}

Las relaciones entre el África mediterránea y Valencia, afianzadas en siglos anteriores, se llevaron, a cabo, básicamente, a partir de los puertos de Orán y Argel; sin olvidar el papel puntual que ejercieron los de Túnez, Tabarca o Ceuta.

\footnotetext{
${ }^{2}$ Velasco HernándeZ, F. (2005). «El auge económico de Cartagena y la revitalización del sureste español en los siglos XVI y XVII», Hispania (Revista Española de Historia), vol. LXV/2, n ${ }^{\circ}$ 220, mayo-agosto, Madrid, pp. 485-513.

${ }^{3}$ SAlvador Esteban, E. (1971). «Datos sobre el comercio con el norte de África en la Valencia del siglo XVI», en I Congreso de Historia del País Valenciano, Valencia, pp. 117-124.

4 Montojo Montojo, V. y Ruiz IbÁÑEZ, J. J. (2009). «Relaciones y agentes comerciales entre Orán y el Reino de Murcia en la primera mitad del siglo XVII», Murgetana, Real Academia Alfonso X el Sabio, nº 120, pp. 111-128.
} 
Recordemos que ya desde la Baja Edad Media se había desarrollado un comercio activo entre las ciudades costeras de la Corona de Aragón y los diferentes enclaves comerciales del Magreb $^{5}$. Este comercio hispano-norteafricano de fines del siglo XV consistía básicamente en una corriente importadora cuyos artículos fundamentales eran el oro africano, los esclavos, productos alimenticios como el trigo, la miel, el azúcar de caña, o los frutos secos. También se importaron semillas, especias, colorantes, materias primas, sobre todo cera, cueros, lino y lana. Otro capítulo importante fue el relativo a las drogas y productos manufacturados, entre los que cabía destacar los cordobanes, las alfombras, los albornoces, o los derivados del cobre. ${ }^{6}$

En el siglo XVI este comercio del Mediterráneo occidental sufrirá modificaciones substanciales. Tenderán a desaparecer tanto el oro procedente del Sudán como los esclavos. Sin embargo, cada vez cobrarán mayor importancia los productos magrebíes de bajo precio pero de no menor importancia, entre los que conviene remarcar por su importancia, los cereales; sobre todo, el trigo y la cebada, aunque también hubo otros alimentos importados que merecen destacarse, como las habas, los dátiles o los garbanzos y, por supuesto, las especias. Asimismo se siguieron importando materias primas entre las que cabe remarcar el lino y la lana magrebíes, o los cueros. También se importaron manufacturas textiles y un sinfín de productos de diversa procedencia, entre los que hay que reseñar la cera, por la importancia que esta tuvo para los servicios religiosos ${ }^{7}$. Un testigo de la época, Diego Suárez, confirma las exportaciones que los magrebíes canalizaban hacia las costas españolas, las cuales consistían, como ya se ha indicado, básicamente en productos alimenticios, materias primas $\mathrm{y}$ artículos manufacturados ${ }^{8}$. Su testimonio, por tanto, nos aproxima a la realidad comercial valenciana con el norte de África y oraní en particular.

${ }^{5}$ AlONso ACERo, B. (2006). «Trenes de avituallamiento en las plazas españolas de Berbería». En Guerra y Sociedad en la Monarquía Hispánica. Política, estrategia y cultura en la Europa moderna (1500-1700), vol. I, Madrid, pp. 739-766.

${ }^{6}$ En términos parecidos a los expresados se manifiestan diferentes historiadores: Además de los consabidos esclavos, también grandes cantidades de cereales, cera, dátiles, cuero y mercaderías de lujo como la seda, el oro o las piedras preciosas salían de forma periódica desde el continente vecino en busca de los mercados de la Cristiandad. DouforCQ, C. E. (1966). L'Espagne catalana et le Magreb aux XIII ${ }^{\mathrm{e}}$ et $\mathrm{XIV}^{\mathrm{e}}$ siècle, París; LOPEZ DE CoCA CASTAÑER, J. E. (1978). «Relaciones mercantiles entre Granada y Berbería en época de los Reyes Católicos», Baética: estudios de arte, geografía e historia, I, Málaga, pp. 293-311; LOPEZ DE COCA CASTAÑER, J. E. (1978). «Esclavos, alfaqueques y mercaderes en la frontera del mar de Alborán (1490-1516)» Hispania, vol. XXVIII, nº. 139, Madrid, pp. 275-300.

${ }^{7}$ MARTín CORRALES, E. (1996). «El comercio español con Tetuán y el litoral del Rif en los siglos XVI y XVII», Coloquio de historia de Tetuán. Siglos XVI y XVII, pp. 3-28.

${ }^{8}$ Alonso ACERO, B. (2006). «Trenes de avituallamiento...», pp. 739-766. 


\section{FUENTES.}

Los registros documentales utilizados para el estudio del comercio marítimo, reglamentado ${ }^{9}$, entre Valencia y Orán, durante el seiscientos y el trienio 1700$1703^{10}$, han aportado interesantes resultados para la reconstrucción, de lo que debieron ser, las relaciones comerciales entre los enclaves costeros aludidos. Los fundamentos documentales del presente trabajo se centran principalmente en la serie Peatge de Mar ${ }^{11}$, perteneciente a la sección del Maestre Racional, cuyos originales se conservan y custodian en el Archivo del Reino de Valencia.

Haciendo una valoración global, el estado de estas fuentes es óptimo; sólo algunos volúmenes se encuentran deteriorados por causa de la humedad y los insectos, es el caso de los legajos que refieren a los años 1604, 1613, 1630, 1646 y 1656; aunque algunas página se pueda leer, es aconsejable no trabajar con ellos hasta que se microfilmen o se restauren. En cada uno de los registros suele haber tres apartados.

En el primero de ellos, constan los datos generales; a saber, la fecha, el modelo de embarcación, el nombre del patrón, la procedencia del navío y el impuesto que debía abonar. Esta tasa variaba según el tipo de nave. Un segundo apartado informa sobre el remitente, la cantidad y naturaleza de las mercancías, así como sus destinatarios. El objetivo de todo el registro era adjudicar la tasa que se debía abonar, tanto por la entrada del bajel como del pago por cada una de las mercancías. Es por ello que, junto con la consignación del pago se hacía constar la fecha en que se abonaba. Los registros incluyen un tercer apartado en el que se anotan los acontecimientos sucedidos en la travesía. En ocasiones las naves, se ven obligadas a protegerse en un puerto o apartarse de su ruta debido a las inclemencias climáticas, al ataque o presencia corsaria ${ }^{12}$. Las circunstancias son diferentes. En

${ }^{9}[. .$.$] hay que tener en cuenta el comercio clandestino y el contrabando que, contrarrestaron las$ prohibiciones temporales y/o parciales de comerciar con el Maghreb. MARTín CORRALES, E. «Una aproximación al comercio Hispano-Marroquí en el siglo XVII», El siglo XVII Hispanomarroquí, Serie: Coloquios y Seminarios, $\mathrm{n}^{\circ}$ 64, Coordinador: Mohammed SALHI, Rabat, pp. 177-202.

${ }^{10}$ Aunque el trabajo emprendido se centra en el siglo XVII, hemos incluido los primeros años del siglo XVIII, trienio (1700-1703) con el que se cierra la serie del Peatge de Mar.

${ }^{11}$ Para una mayor información sobre los legajos analizados, consultar. BLANES ANDRÉS, R. (2010). Valencia y el Magreb. Las relaciones comerciales marítimas (1600-1703), edi. Bellaterra, pp. 23-26.

12 Por ser de sumo interés y estar relacionado con el trabajo que vamos a desarrollar hemos recogido, por orden cronológico, los diversos acontecimientos relacionados con la presencia de naves corsarias de origen musulmán: Dimecres 29 de març de 1634 vingué la barca del patro Jaume Castellar ve del puerto de Portugal diu lo patro que ha tocat a Lartaçia per un vaixell de moros y 
ocasiones el litoral mediterráneo o atlántico estaba castigado por la alguna enfermedad infectocontagiosa (la peste); en este caso las embarcaciones procuran no acercarse a ninguna dársena afectada por la epidemia, haciéndolo constar el patrón bajo juramento a la llegada. Cuando surgen dudas sobre la autenticidad del testimonio, se le obliga a fondear a cierta distancia de la playa-puerto y dejarlo allí durante un tiempo razonable, conocido por cuarentena. Transcurrido este lapso y si la infección no ha afectado a ningún integrante de la tripulación o del pasaje, el patrón recibe el permiso para desembarcar a tierra, tanto las personas como las mercancías $^{13}$.

El análisis de las fuentes consultadas nos permite discernir las características de las naves que transportaron los múltiples artículos hasta los depósitos valencianos, los espacios de contención y distribución, a los propietarios de los productos, así como los establecimientos encargados de su venta y posible redistribución a otros lugares.

\section{TIPOLOGÍA DE LAS EMBARCACIONES QUE INTERVINIERON EN LAS EXPORTACIONES ORANÍES.}

A pesar de su supuesta analogía y de la posibilidad que tienen las embarcaciones de atravesarlo en todas las direcciones, el mar tiene sus rutas. Es cierto, que algunas son poco concurridas; otras, por el contrario, se encuentran consolidadas por un intenso tránsito. En el siglo XVII las diferencias eran menos acentuadas entre los grandes puertos dotados de unas infraestructuras importantes que servían de confluencia a todo un territorio y los puertos secundarios reducidos a simples embarcaderos provisionales o playas abiertas, sin apenas instalaciones ${ }^{14}$. En todos partes las infraestructuras eran muy primarias, eran muy escasos los puertos de piedra. Las condiciones económicas eran las que favorecían una cierta aglutinación del tráfico.

Alacant y Denia. Archivo del Reino de Valencia (A.R.V)., Maestre.Racional (M. R.), Peatge de Mar (P. M.), Año 1634, 10985, f. 123-r.

Dissabte 7 de gener de 1645 vingue la barca del patro Pere Juan Marti ve de Mallorca y Denia. Anasen per el mal temps y cativaren los moros. A.R.V., M.R., P. M., Año 1645, 11017, f. 97-r.

Dimecres a 26 de juliol de 1687 vingue la saetia del patro Llacer Armerito de Lisboa, he dix que el haver vengut a esta placha es solament per guardarse de una galera y una saetia de moros que ya via fora. A.R.V., M.R., P. M., Año 1687, 11.084, f. 148-r.

${ }^{13}$ Dimarts a 26 de novembre de 1677 la fragata del patro Frances Gabert ve de Argel y Alacant; fonch atiesa a platica la gent de la fragata avent fet primer la cuarentena. M.R., P. M., Año 1677, 11041, f. 102-r.

${ }^{14}$ Blanes ANDRÉs, R. (2010). Valencia y el Magreb...., p. 45. 
El Grao de Valencia contaba con un puerto-playa; es decir, no había un puerto con muelles de piedra donde podían atracar las embarcaciones. Un espigón de madera penetraba en el mar, pero los barcos quedaban a una cierta distancia de la orilla para no encallar. No obstante estas dificultades, a Valencia arribaban numerosas naves, tanto comerciales y militares. ${ }^{15}$ En este sentido, hay que remarcar que, a lo largo del siglo XVII la cantidad de navíos en movimiento por el puertoplaya valenciano, que hemos controlado por medio de las fuentes estudiadas, procedentes de Orán, es de 220 unidades. Ahora bien, ante este hecho constatado, que llegaron 220 bajeles procedentes de Orán, caben dos posibilidades, analizar el dato cuantitativo o, ir más allá y estudiar de qué tipo de naves se trataba y qué implicaciones tenía. La documentación permite el estudio de la tipología de los barcos, por lo que haremos dicho análisis extrayendo, por supuesto, las conclusiones que de él se desprenden.

El examen de los navíos que se registraron durante el periodo acotado se aborda a partir de los diversos medios de propulsión manejados. Para ello aplicaremos la clasificación realizada por el capitán de las galeras pontificias, Pantero Pantera ${ }^{16}$, que en su estudio sobre arte naval de 1613 proyectó una ordenación de los diferentes buques que surcaban el Mediterráneo y el Atlántico, agrupación que se vincula considerablemente al catálogo de embarcaciones que nos han ido mostrando la documentación aludida con anterioridad.

Según la clasificación hecha por el mencionado capitán, podemos distinguir tres grupos: en primer lugar las embarcaciones que navegaban con velamen cuadrado o mixto (utilizaban al mismo tiempo la vela cuadrada y la triangular); en segundo término las que navegaban con aparejo triangular o latino; y en último lugar las que empleaban, principalmente, el remo como elemento de propulsión y la vela triangular como sistema de apoyo de aquél. Ahora bien, la profesora Emilia Salvador apunta que estos tres grupos se pueden quedar reducidos a dos, el que navega mediante remos y, en ocasiones con ayuda de la vela -casi siempre triangular-, y el que singla solo mediante vela. En este último caso puede ser que utilice vela cuadrada o mixta o bien que se trate de naves que sólo se impulsan con velas triangulares o latinas. ${ }^{17}$

15 BoIra, J. V. y SERRA, A.. (1994). El Grau de València. La construcció d'un espai urbà, Edicions Alfons el Magnànim, Generalitat Valenciana, València, p. 39.

${ }^{16}$ PANTERA, P. (1613). L'armata navale del capitan Pantero Pantera, Roma, cap. IIII (sic), pp. 40-48.

17 SAlvador Esteban, E. (1972). La Economía Valenciana en el siglo XVI (Comercio de Importación), Valencia., p. 183. 
En los cuadros subsiguientes vamos a exponer el resultado numérico de los grupos en que hemos incluido el catálogo de embarcaciones en la documentación consultada, abordando, como ya se ha indicado su posterior estudio y comentario

Por lo que respecta al primer apartado de naves hallamos:

\section{Embarcaciones con velas latinas}

\begin{tabular}{cc}
\hline Tipos & Unidades \\
\hline Barcas & 65 \\
Gánguil & 2 \\
Jabeque & 3 \\
Laúd & 2 \\
Saetía & 56 \\
Tartana & 28 \\
\hline Total & 156 \\
\hline Embarcaciones con velas cuadradas-mixtas \\
\hline Tipos & Unidades \\
\hline Carabela & 1 \\
Galeonet & 1 \\
Patage & 1 \\
Pinco & 2 \\
Nao & 14 \\
Naveta & 2 \\
Vexell & 1 \\
\hline Total & 22 \\
\hline
\end{tabular}

Y en lo referente al segundo grupo de navíos encontramos:

\begin{tabular}{cc} 
Embarcaciones con remos y & aparejo latino \\
\hline Tipos & Unidades \\
\hline Bergantín & 34 \\
Falúa & 3 \\
Fragata & 3 \\
Góndola & 1 \\
\hline Total & 41 \\
\hline
\end{tabular}

Solo en un caso no se especifica la tipología de la nave, concretamente la embarcación que se asentó en los registros, el 1 de enero de 1673.

El primero de los grupos (con aparejo latino y velas cuadradas-mixtas) suma un total de 178 navíos y dentro de éste la supremacía la ostenta la vela triangular con 
un total de 156 buques. El segundo grupo (remos y aparejo latino) no supera el medio centenar, concretamente 41 embarcaciones. Considerando globalmente los dos grupos, el $71 \%$ corresponde a velas triangulares, el $10 \%$ a velas cuadradasmixta y el $19 \%$ a remos (GRÁFICOS 1 y 2).

Dejando a un lado las arduas discusiones metodológicas que sobre los diversos tipos de buques del seiscientos existen, trataremos de establecer algunas peculiaridades genéricas que den sentido a esta variedad de nombres, con que nos dispensa la documentación. Testimonio, bastante conciso, como hemos podido comprobar, ya que no va más allá de la simple denominación de la unidad arribada al puerto-playa de Valencia.

Como ha podido observarse el primer grupo de embarcaciones es, con mucho, el más numeroso. La mayoría de los analistas del Mediterráneo y de los navíos que lo surcan en todas direcciones, al presentar íntegramente este subgrupo de buques, se ciñe a calificarlos como reducidas naves elegidas para el comercio de cabotaje. Esta generalización da lugar a dudas cuando se trata de precisar la diferencia tipológica debido a la falta de datos, lamentable, si tenemos en cuenta que este tipo de embarcaciones es la más habitual en el comercio de importación valenciano en términos generales y, más concretamente, desde Orán.

\section{Gráfico 1: Tipología de las embarcaciones procedentes de Orán (1600-1703)}

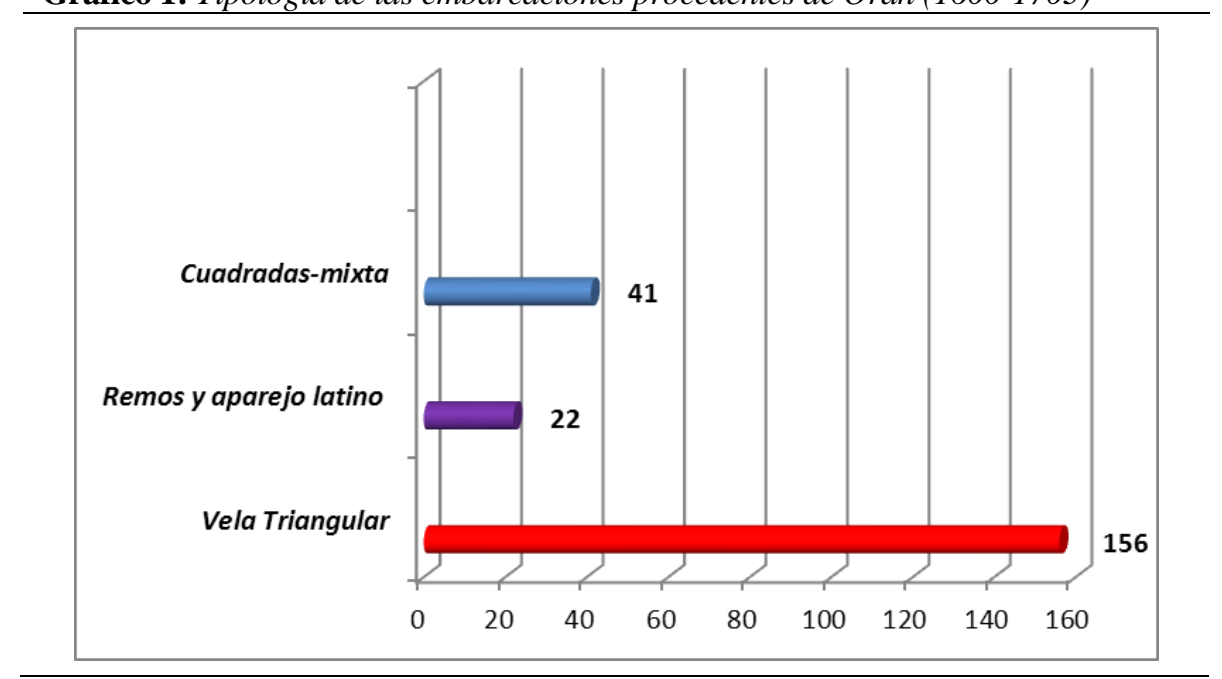


La superioridad que alcanzaron este tipo de naves en el tráfico entre Valencia y Orán se manifiesta de forma evidente al considerar los resultados alcanzados: el 71 $\%$ de los buques que llegaron a nuestro puerto, fueron unidades de este prototipo. De entre ellas, la barca es la que alcanza el mayor número: 65 unidades y el 41,6 \% del total. Le sigue, la saetía, con 56 y un $36 \%$ del conjunto. La tartana ocupa el tercer lugar, a una distancia considerable, con 28 unidades y un $18 \%$. Por debajo de los anteriores encontramos el jabeque que alcanza las 3 unidades y un $2 \%$ mientras que el gánguil y el laúd son dos modelos cuya presencia resulta poco significativa al registrarse, en ambos casos, 2 unidades respectivamente lo que supone el $1,2 \%$ del total.

Por lo que respecta al segundo grupo, es decir, las embarcaciones de aparejo cuadrado-mixto, son menos numerosas; concretamente son veintidós naves, que suponen el 10 por ciento del total de las naves arribadas de Orán puesto que estas naves son más características de la navegación atlántica. De los modelos anteriormente reseñados y como apuntan las cifras logradas, el modelo que con más frecuencia menciona nuestros documentos es la nao. Así de los veintidós navíos que hemos conseguido determinar, las naos monopolizan por sí solas el 66,6 por cien de aquellos, con catorce embarcaciones. El resto, solo tienen una presencia testimonial en nuestra playa. El pinco y la naveta se manifiestan en dos ocasiones con el nueve por cien y la carabela, el "galeonet", el "patage" y el "vexell" con una sola presencia y el $4,6 \%$.

Gráfico 2: Porcentaje de las embarcaciones procedentes de Orán (1600-1703)

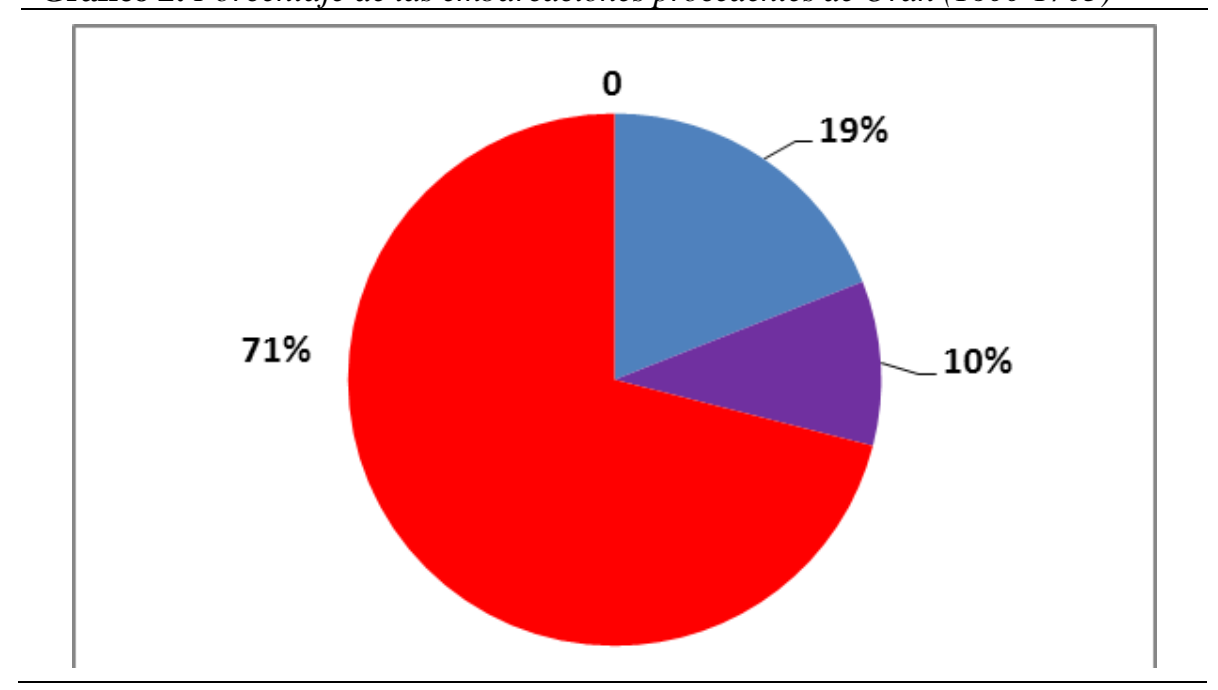


El último apartado, es decir, el correspondiente a las naves que adoptaban como medio de propulsión los remos y la vela triangular, nuestros resultados les atribuyen un $19 \%$ y un total de 41 unidades frente a un $71 \%$ y 156 embarcaciones con disposición latina. Esta diferencia se reduce cuando la comparación se realiza con los navíos de apresto cuadrado-mixto, ya que sólo hay una diferencia del $9 \%$ favorable a estos últimos. En este grupo, la embarcación que tiene mayor presencia en nuestros documentos es el bergantín con un $83 \%$ y 34 unidades. Le sigue la falúa y la fragata con 3 navíos y el 7,3\%. La góndola tiene una representación anecdótica con el 2,4\% y un solo buque.

Profundizar en los resultados alcanzados, excede del ámbito del presente estudio, pero cabe afirmar la preponderancia de las embarcaciones de tradición mediterránea sobre los oceánicos, la supremacía de las de mediano y pequeño fondo sobre las de voluminosos bastimentos y la relativa cercanía geográfica entre Orán y Valencia debió beneficiar los recorridos directos. No obstante, tras un detallado análisis de los resultados, nos lleva a apuntar que la travesía entre las dos orillas de la ruta, no siempre se resolvía en un itinerario exclusivo. Por el contrario, tuvo gran importancia la navegación de cabotaje, aunque las fuentes se muestran escasamente reveladores en relación a este tema. Así de las 220 embarcaciones procedentes de Orán, 86 hicieron escala en 8 puertos diferentes antes de llegar a Valencia; de estos Alicante será intermediario en 38 ocasiones (44,1\%) entre 1600-1700' Denia en 36 $(41,8 \%)$ entre 1604-1682, Cartagena en $7(8,1 \%)$ y Morvedre, Cádiz, Cullera, Jávea y un puerto no identificado lo serán en una sola oportunidad $(1,2 \%$ respectivamente).

\section{PATRONES.}

Lo primero que cabe indicar respecto a los capitanes que mandaban sus buques desde el puerto de Orán, es que arriesgaron en múltiples ocasiones, su vidas, la de sus marineros, sus embarcaciones e, incluso, los artículos que transportaban. De entre todos los patrones documentados cabe resaltar a Juan Reboll quien a bordo de su tartana y, en una ocasión, de una saetía, fondeó en el Grao de Valencia en siete ocasiones, en el periodo comprendido entre 1670-1672, así como en el año 1680. Los géneros transportados se reducen a grandes cantidades de trigo (un total de 824 cahíces), dátiles y lana sucia. El comerciante que solicitó con mayor asiduidad sus servicios fue Benito Perrier, personaje que lo encontraremos en las dos orillas de este comercio, como remitente y destinatario de trigo y dátiles. Patrón que no terminará su periplo en nuestra ciudad, sino que seguirá, en diversas ocasiones, hasta Barcelona y Marsella. Damiá Castillo nos visitará en cinco oportunidades, todas ellas en la década de los veinte, de forma irregular entre 1621-1626. Desembarcando diversos artículos como: mantas, plumas, dátiles, cueros o trigo. 
De los mercaderes que facturaron los productos listados destacan el propio patrón, Vicente Pascual y Pere Gonzalo. Las llegadas a nuestro puerto-playa se irán reduciendo, así encontraremos, Bertomeu Paganeto en cuatro ocasiones. El primero al mando de su nao fondeará en el Grao ante el reclamo de realizar un buen negocio al trasladar los moriscos expulsados a las costas de Berbería, centrando sus actuaciones a lo largo del postrero trimestre de 1609. Otros titulares de naves son Pedro Antich, March Coll, Juan Frances, Frances Genovés, Pere Vila o Frances Zaragoza.

No podemos cerrar este apartado sin mencionar a los patrones que (encuadrándonos en el campo de la conjetura) sospechamos unidos por lazos familiares como la pareja apellidada Abella (Andreu y Bertomeu), los Bonet (Antonio, Juan y March); Ferrer (Jorge, Antonio, Pedro, Juan y Sebastián); March (Gaspar, Lorena y Ricardo) o Lauros (Bertomeu, Domergue, Juan y Pierres) todos ellos interrelacionados con la ciudad de Orán.

\section{PRODUCTOS DE IMPORTACIÓN.}

En la playa-puerto de Valencia se desembarcaron decenas de artículos diferentes durante el seiscientos y principios del setecientos procedentes de Orán; analizar individualmente cada uno de ellos, resultaría una tarea que excedería de los límites del presente trabajo. Por ello, hemos seleccionado para su estudio los que parecen haber tenido una dimensión mayor. Los dos sectores del comercio valenciano que se impusieron a los restantes, fueron la alimentación y determinadas mercancías industriales, a los que vamos a prestar particular interés.

El movimiento comercial más trascendental era invariablemente el que certificaba el abastecimiento alimenticio de la ciudad. Dentro de economías con escasos y a menudo precarios excedentes agrícolas, las concentraciones de población urbana se encontraban, periódicamente, en una situación muy arriesgada.

Valencia, al igual que la mayoría de las ciudades del seiscientos, tuvo que combatir la penuria alimenticia, teniendo que superar dificultades de toda índole para que sus ciudadanos estuvieran abastecidos regularmente, alejando las crisis de subsistencia que periódicamente tocaban a las puertas de las grandes urbes.

Como ya se ha indicado, las importaciones norteafricanas fueron variando a lo largo de los siglos ${ }^{18}$. Del oro y de los esclavos a finales del siglo XV y gran parte

\footnotetext{
18 MARTín CORRALES, E. (1997). «Una aproximación al comercio Hispano-Marroquí en el siglo XVII», El siglo XVII Hispanomarroquí, Coordinador: Mohammed Salhi, Serie: coloquios y Seminarios, ${ }^{\circ} 64$, pp. 177-202.
} 
del siglo XVI se fue pasando paulatinamente a los cereales. Una argumentación que se aproxima a la realidad comercial valenciana, aunque con algunas puntualizaciones notables, que vamos a ir desmenuzando al profundizar en los artículos más significativos llegados desde el presidio de Orán. Así, las importaciones procedentes del Oranesado, en el período señalado, ponen de manifiesto que los artículos que tuvieron más peso fueron las gramíneas, destacando esencialmente el trigo, a pesar de que su papel, en el montante global de las importaciones valencianas, jugará un papel discreto ${ }^{19}$. La cebada por su parte tuvo un protagonismo muy pobre, apareciendo en momentos puntuales con cantidades poco relevantes.

El profesor Eloy Martín Corrales nos recuerda que uno de los principales motivos de la presencia hispana en el norte de África fue el interés en disponer del grano magrebí, siempre incierto en la península y, muy especialmente en el Levante español $^{20}$. Valencia no fue indiferente a las oportunidades cerealísticas que ofrecía la ribera norteafricana. Un abastecimiento que estaba por encima de credos políticos y religiosos ${ }^{21} \mathrm{y}$, especialmente, de prohibiciones por parte de una curia eclesiástica que no sufrirá los racionamientos de sus feligreses en épocas de carestía.

De este modo, en el siglo XVII la adquisición de trigo se fue configurando como la actividad más importante en las importaciones valencianas oriundas del

19 En el segundo cuarto del seiscientos ocupaba el quinto lugar, en cuanto a las áreas suministradoras de trigo a Valencia, por detrás de la península italiana (insular-peninsular), el norte de Reino de Valencia, Cataluña-Rosellón y el sur del Reino Valenciano. Entre 1626-1650, el trigo procedente de este espacio alcanza la cantidad de 38343 cahíces. BlANES ANDRÉs, R. (2002). «Importación marítima de cereales en la Valencia del Segundo Cuarto del Seiscientos (1626-1650)». VII ${ }^{a}$ Reunión Científica de Historia Moderna que se realizó en Ciudad Real entre el 3 y el 6 de Junio de 2002, I vol., pp. 481- 499.

${ }^{20}$ Martín CoRrales, E. (2001). Comercio de Cataluña con el Mediterráneo Musulmán (siglos XVI-XVIII). El comercio con los "enemigos de la fe", Barcelona, 2001, p. 309.

${ }^{21}$ Cuando Pedro IV el Ceremonioso, se apoderó de las Baleares, en 1343, [...] otorgó un Privilegio Real en Zaragoza, el cual tendrá un importancia excepcional para las futuras relaciones comerciales entre Mallorca y Berbería, según el cual, los pobladores de la isla podían comerciar con cualquier tipo de enemigo para poder obtener provisiones. También este mismo año otorgó franquicia a los sarracenos que quisiran venir a comerciar a Mallorca, sujetos tan sólo al derecho de entrada que era de 10 sous 6 diners, [...] Archivo Histórico del Reino de Mallorca, Códices: Cod. 3 Rosselló Vell, F. 215 y Cod. 4 Rosselló Nou, f. 166 y Llibre dels Ordinaccions del Regne, f. 139 y Lletres Reals II, f. 40 y 108. Citado por JUAN VIDAL, J. (1974). «El comercio entre Mallorca y África del Norte en los siglos XVI y XVII», I Congrès d'Histoire et de Civilisation du Maghreb, Túnez, pp. 73-92. 
Norte de África ${ }^{22}$ y especialmente del enclave español de Orán. La justificación podemos encontrarla en diversas causas, la más inmediata es la ancestral complejidad de abasto frumentario de Valencia, siempre necesitada de adquisiciones exteriores en un espacio temporal caracterizado por la sucesión de malas cosechas lo que daba como resultado, las temidas crisis alimenticias. Simultáneamente, y a pesar de la sangría sufrida a principios de la centuria con la expulsión de los moriscos y de las virulentas enfermedades infectocontagiosas que la flagelaron (especialmente la peste de 1648), Valencia percibió un positivo incremento demográfico en este siglo, especialmente en su segunda mitad, dando lugar a un aumento en la demanda de cereales. Un segundo elemento a tener en cuenta es la cercanía entre el litoral valenciano y el oraní, lo que posibilitaba mandar rápidas empresas en busca de grano. En último término las particularidades de estos áridos los hacía especialmente idóneos para almacenarse durante espacios dilatados de tiempo.

La carta de tráficos comerciales, transportando cereal, procedentes del enclave de Orán (solo hemos anotado los años que llegan a Valencia, embarcaciones con grano), es la siguiente:

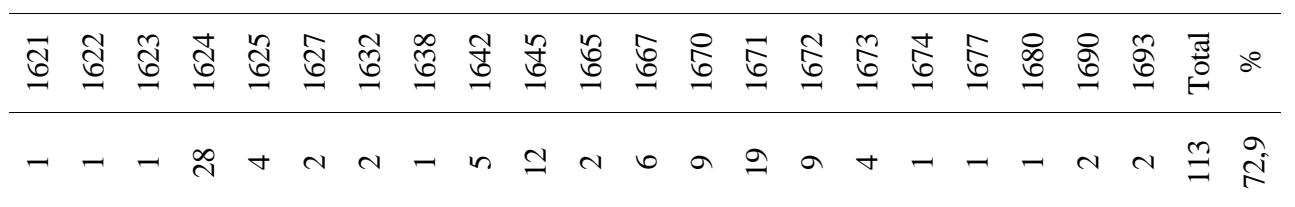

Tabla que nos lleva a afirmar que Orán, destaca por encima del resto de puertos norteafricanos expedidores de trigo ${ }^{23}$ al superar el centenar de embarcaciones

\footnotetext{
${ }^{22}$ Numerosas son las noticias, tanto de carácter cualitativo como cuantitativo, que ejemplifican la continua llegada de cereales berberiscos. En 1669 el cónsul francés en Alicante declaraba: "Siempre que en España falta granos llega cierta cantidad de navios franceses y de otras banderas que cargan en Túnez [...] y Tabarca, descargando desde Cataluña hasta Cádiz.

Diecisiete años más tarde, un nuevo informe, esta vez del cónsul galo en Barcelona, ratifica lo anterior: "Este año abunda el aceite, el trigo y las verduras, pero cuando escasean o cuando se permite su importación de Francia, se carga grano para acá en Narbona u otras partes como Cerdeña, Nápoles, Sicilia o Berbería”. KAMEN, H. (1981) La España de Carlos II, Barcelona, Crítica, pp. 187-188 y 193-195. Citado por E. MARTín CoRRALes. Comercio de Cataluña con el Mediterráneo Musulmán.., p. 313.

${ }^{23}$ Tabarca con 29 navios y el 18,7 \% del total, le sigue, Argel con 6 unidades y el 3,9\%; Túnez y Berbería (no se especifica los nombres del puerto) ambos con 3 y el 1,9\% y con el nombre de costa de Berbería 1 y el 0,7\%. BLANES ANDRÉS, R. (2010). Valencia y el Magreb..., p. 93.
} 
(exactamente 113 unidades), lo que supone las tres cuartas partes de todas las naves transportadoras de trigo que llegaron al Grao de Valencia, percibiéndose una regularidad en los arribos, sólo rota en espacios de tiempo muy concretos. Sobresaliendo los años 1624 con 28 navíos (lo que supone el $18 \%$ del total), 1645 con $12(7,8 \%)$ y 1671 con $19(12,2 \%)$. El volumen importado desde el puerto oraní, se eleva a 31.536 cahíces, lo que supone el 44,8 \% del total, que alcanzó la cantidad de 70436 cahíces $^{24}$.

Sin lugar a dudas, el granero principal para nuestra ciudad fue el puerto de Orán $^{25}$, de donde llegaron las partidas más importantes de los trigos de mar que se adquirieron $^{26}$, para su estudio, hemos confeccionado una tabla con los años y cantidades expedidas; teniendo como inicio 1621 y como final 1693, extremos donde se intercalan décadas de importaciones estables, con otras donde la presencia de navíos frumentarios es discreta y en ocasiones nula. Para una mayor comprensión hemos recopilado los datos obtenidos en el cuadro que adjuntamos:

Comercio que se inicia en la década de los años veinte, concretamente el 28 de mayo de $1621^{27}$, con anterioridad a esta fecha no se ha detectado la llegada de buques procedentes de Orán cargados con grano (vacio comercial, cuyas causas, exceden del objetivo de este trabajo). Entre 1621 y 1627 se negociaron 8358 cahíces de trigo, siendo 1624 el más activo con 6935 cahíces (el 9,8\% del total), seguido de 1625 con 1156 cahíces (el 1,6\%), los restantes oscilan entre los 100

${ }^{24}$ Tabarca exportó 27.357 cahíces (38,4\%); Argel 7.357 (10,4\%); Túnez 2.370 (3,3\%); Berbería $1.946(2,7 \%)$ y Costa de Berbería 125 (0,17\%). Ibídem, p. 94.

25 Con Orán, el movimiento comercial estaría motivado por las necesidades de aprovisionamiento cerealista de la capital valenciana, puesto que desde allí predominaban de modo abrumador las importaciones trigueras. De 1385 a 1391, y siempre según los datos que proporciona la doctora María Dolores López, esas importaciones superaron los 27.000 cahíces, una cifra que supuso el $66 \%$ del total del trigo magrebí llegado entonces a Valencia. IGUAL LuIS, D. (2004). «Navegación y comercio entre Valencia y el Norte de África durante el siglo XV». En TRILlo SAN José, C., (ed.) Relaciones entre el Mediterráneo Cristiano y el Norte de África en época Medieval y Moderna, Granada, pp. 229-286.

${ }^{26}$ Cuando las cosechas musulmanas eran fértiles y abundantes y había un gran número de aduares con seguro del gobernador de Orán, la gran cantidad de grano recogido en el puerto de Mazalquivir facilitaba la provisión de otras fronteras de la Monarquía, caso de las demás plazas cristianas en Berbería, [...], en 1624, la provisión de trigo de Ibiza y Menorca es integramente conseguido en Orán, además de 3600 fanegas de trigo para Melilla. También el grano de Orán sirve para abastecer a la tripulación de galeras, concepto en el que el trigo norteafricano es preferido al de Sicilia cuando las cosechas de los moros de paz han sido buenas, para "aunque en Sicilia haya abundancia de trigo vendrá a ser lo de Oran mucho más barato y se traerá con mas brevedad y menor riesgo. AlONSO ACERO, B. (2006). «Trenes de avituallamiento...», p. 750, 763 y 764.

${ }^{27}$ A. R. V., M. R., P. M., sig. 10971, f. 301 v. 
cahíces de 1621 y los 13 de 1627, año que marca el inicio de un período de inactividad importadora, que se prolongará hasta el segundo año de la década de los treinta ${ }^{28}$, sufriendo un nuevo paréntesis que se prolongará hasta 1638 , donde se registrarán 130 cahíces. Hasta 1642, no encontraremos ninguna referencia a navíos provenientes de Orán, fecha que se desembarcan 3253 cahíces (el 4,6\%). Le seguirá 1645, el más dinámico de todos los estudiados al conseguir una magnitud de negocio de 13408 cahíces (el $19 \%$ ) (el volumen importador fue de tal dimensión que en una sola partida se llegó a trasladar 3400 cahíces $^{29}$ ). A partir de esta fecha nos encontraremos con el ciclo más pobre de lo que resta del seiscientos, veinte años, donde no se gestiona ninguna cantidad de grano procedente del puerto señalado. Tendremos que trasladarnos a 1665 y 1667 para retomar estas transacciones, que aportarán al mercado valenciano 302 y 453 cahíces respectivamente. La década de los setenta (se trajeron 4869 cahíces) se caracterizará por la regularidad en su primera mitad, resaltando $1671^{30}$ con 1722 cahíces (el 2,4 \%). En la segunda mitad sólo se contabilizarán 204 cahíces en 1677. Las facturaciones en los años ochenta se reducen a 200 cahíces en $1680^{31}$. Cerraremos la centuria con los 467 y 92 cahíces de 1690 y 1693.

A modo de conclusión podemos confirmar que el trigo fue el principal producto de importación norteafricano. Hasta tal punto que, según las crónicas de la época,

${ }^{28}$ Importación de trigo (aunque es un volumen pequeño), posiblemente, tuvo lugar como consecuen de la falta de pan que se experimento en 1630, escriviose tambien que perecia la gente por falta de pa: Y el Duque de Gandia mayordomo mayor de la Reyna escrivio; que solo el, aquel dia (lunes 8 de julio), había comido pan en su casa. La sequía sufrida en todo el reino, en 1631, fue tan grande que llegó a cotizarse el trigo a 17 libras y no se halla en el Reyno., Ibídem, p. 184 y 199.

${ }^{29}$ A. R. V. M. R., P. M., sig. 11017 , f. 105 v.

El 1 de mayo de 1645, la nao, bautizada con el nombre de la Emproviso, capitaneada, por el italiano, Julio Marineto fondea en el Grao de Valencia, procedente de Orán (visitando previamente Alicante) con una carga de 3.400 cahíces destinada, a la pareja de comerciantes (de origen italiano) integrada por Juan Cernesio/Sernesio y Escanio Sobregondi.

${ }^{30}$ Un año después, en 1678, llegó a valer a diez y seis libras el cahíz del trigo y huvo dia que en el Almodín no quedó un grano. Diez años después (1688) se vio el trigo tan bajo que se vendía muy bueno a quatro libras el cahíz y a sinco y medio el mejor. BENAVENT, I. y AGRAMUNT, J. (2004). Memoria escrita, historia viva. Dos dietarios valencianos del Seiscientos, Introducción, transcripción y notas a cargo de Emilio Callado Estela y Alfonso Espinera Cerdán, Ajuntament de València, Valencia, p. 38y 47.

${ }^{31}$ Recordemos que en este año de 1681, [...] sitiado el moro Orán y muerto a su governador en su defensa, se embió de Valencia un socorro de duzientos cahices de trigo. Y el conde de Aguilar perdonó a Ramonet y su cuadrilla y les embió con dicho socorro. Y embarcó muchos vagamundos martes 22 de abril. Ibídem, p. 42. 
en 1630 el sultán de Marruecos ofreció al monarca español todo el trigo que necesitase en España ${ }^{32}$.

Gráfico 3: Trigo procedente de Orán

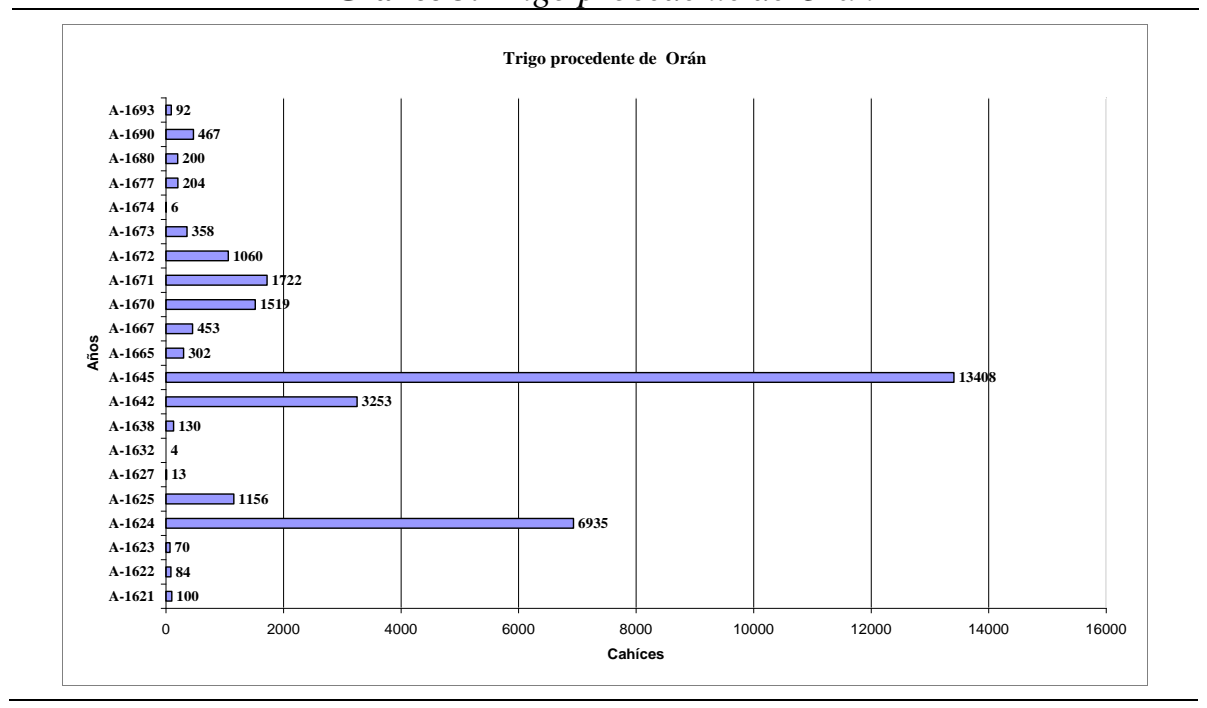

\section{LOS HOMBRES DE NEGOCIOS.}

La nómina de comerciantes que hicieron posible este intercambio, desde ambas dársenas, es muy amplia. En las dos orillas encontramos hombres cuya presencia es esporádica, organismos civiles, en alguna ocasión encontramos algún miembro de la nobleza, a título meramente anecdótico al miembro de una institución religiosa (el padre Felip Tolsa, de la congregación de San Agustín, que compró, en Orán, 17 cahíces de trigo para su comunidad ${ }^{33}$ ), y los verdaderos dinamizadores de esta ruta, los grandes mercaderes tanto a título individual como asociados con otros mercaderes. Desde la capital del Reino valenciano nos hemos vinculado a un registro de remitentes muy extenso; destacando de entre todos ellos Franco Bartolini/Bartola, que tramitará 3557 cahíces, a mediados de 1621, el último trimestre de 1624 y el mes de febrero de 1645, destinados al mercader valenciano

${ }^{32}$ MATIAS De SAn FRANCiSCo (1644). Relación del viage espiritual, y prodigioso, que hizo a Marruecos el Venerable Padre Fray Juan del Prado, Predicador, y primer Provincial de la Provincia de San Diego del Andaluzia. Escrita por el Padre Fray..., Madrid, Francisco García, Impresor del Reyno, p. 209.

33 A. R. V., M. R., P. M., sig. 11041, f. 20 r. 
Pedro Antonio Juliá. Las cantidades expedidas oscilaron entre un mínimo de 3 cahíces (el 5 de diciembre de 1624) y un máximo de 400 (el 12 y el 20 de diciembre de 1624). En todas las ocasiones la ruta seguida se desarrollará entre OránDenia-Valencia, rompiéndose dicha dinámica en un solo viaje donde el puerto intermedio se sustituyó por Jávea (el 20 de diciembre de 1624). Con un volumen de trigo inferior, encontramos a Vincenci Pascual, natural de Italia, quien gestionará, entre 1624, 1625 y 1627, 2393 cahíces, para diversos mercaderes afincados en valencia, como es el caso de la familia de los Cernesio/Sernesio; Francisco y Constantín que recibirán, entre 1624 y 1625,1252 cahíces y Juan Cernesio y Ascanio/Escanio Sobregondi, 8 cahíces en 1642. A esta corporación familiar les siguen a título individual, el manifestado, Pablo Antonio Julia, y, los aludidos, Juan Francisco Baltasano, Jaime Salvador que en 1624 recogerán, en dos envíos cada uno 651, 275 y 52 cahíces respectivamente. Cerraremos este listado con Llacer del Mor y Antoni Valles que recibirán pequeñas cantidades de trigo.

El tercer puesto lo ocupará Juan Escrig, que interpretó el doble papel de remitente y destinatario durante la década de los setenta, introduciendo en el mercado valenciano un total de 2019 cahíces. También señalaremos a Benito Terrier y Juan Batiste Fabrega, que en los años setenta adquirirán y tramitarán 844 y 563 cahíces. Otros mercaderes y sus homólogos en Valencia pueden ser Josep Alvaro-Pere Fabrega; Antoni De Usaiz-Pedro-Antonio Julián; Brain Elva-Juan Batiste Moiselo; Claret Sorilles-Antoni Calvi; Josep Ibarra-Llacer del Mor o Juan Gaço-Francisco Gauchier.

\section{LA IMPORTACIÓN DE OTROS ALIMENTOS.}

El abastecimiento de cebada desde el Norte de África, será monopolizado por Orán de donde zarparán un total de 9 embarcaciones, cargadas con 1456 cahíces, que se distribuirán, de forma aleatoria, entre 1601 y 1664; centrándose la mayoría de las importaciones en los años treinta (concretamente 1631, 1632 y 1634), 1031 cahíces lo que supone el 71,5\%. La mayoría de las travesías realizaron escalas en Denia, en Alicante o Cartagena. Las personas implicadas en este intercambio aparecen en escena en una sola ocasión, así Juan Pinto se relacionará con Miguel Juan Yuesa (1601), Pedro Parexo con Llacer del Mor (1631), el sargento del ejército Antonio Mingot con Don Francés Castelló y Don Juan Espinosa (1632), Vicente Pascual con Don Francisco Falcó (1632), Bartolomé Baltasar con Jaume Beltrán (1634), el patrón Antoni Bonet remitente y destinatario al mismo tiempo (1634), el capitán Sansón Len con Juan Batiste Moiseli/Moiselo (1645), el patrón Damia Fontanelles tramitará íntegramente 175 cahíces (1645) y, por último, el Virrey (no se especifica de que lugar) para él mismo (1664). 
Otra gramínea procedente de Orán es la avena, que llega a Valencia esporádicamente en 1621, 1671, 1674 y 1683, totalizando un volumen de 490 cahíces, tramitado enteramente por Vicente Domingo menor, Luis Buiguet, Pere Arnau Escrig y Josep Bonilla.

El enumerado de mercancías de origen vegetal es muy amplio, aunque en ningún momento de la centuria desbancarán de las importaciones a los cereales. De entre los más tramitados, subrayaremos los dátiles, un fruto seco muy apreciado por los valencianos de la época, cuyo consumo era bastante asiduo, especialmente entre los estratos sociales más bajos y los numerosos miembros de las órdenes religiosas ubicados en la ciudad; un recurso alimenticio en las épocas de subsistencia donde todo producto que proporcionara las virtudes nutritivas necesarias para la vida, era bien venido y mejor consumido.

El comercio del dátil es permanente desde la Edad Media ${ }^{34}$, importación que se afianzará a lo largo del quinientos y del seiscientos, siendo distribuidos por todo el Mediterráneo oriental y más allá de la frontera que marca el Estrecho de Gibraltar entre el Mar Interior y el Océano Atlántico.

$\mathrm{Su}$ presencia, en los cargazones procedentes de las dársenas norteafricanas se inicia en 1600 y se prolongará a lo largo de la centuria, con mayor o menor fortuna hasta 1693, año último que nos indicará el final de este intercambio en la documentación manejada. Estas exportaciones se focalizarán en cuatro puntos concretos de la costa norteafricana: Orán, Argel, Tabarca y Túnez. Destacando Orán (con el 91 \% del volumen tramitado) especialmente a partir de 1610, donde la presencia de embarcaciones con dátiles procedentes de esta dársena son permanentes, en el Grao valenciano, hasta 1693. Las cantidades tramitadas se elevan a 9504,5 arrobas, 69 estives y 1 caxeta. De las personas implicadas en este negocio lo primero que llama la atención es la ausencia de los grandes mercaderes y el número de personas a nivel particular que adquieren cantidades de poca

\footnotetext{
${ }^{34}$ El mercader mallorquín Huguet Pont, nos revela [...] las estrategias de un negociante insular a mediados del siglo $X V$. [...]. Su relación con el Norte de África es constante y prácticamente siempre sobre las mismas bases de relación: exportación de plata amonedada (en cuarts), en barra (en riels) y trabajada [...] e importación de oro, cera, dátiles, lana berberisca, grana, [...]. CATEURA BENNÀsser, P. (2000). «Valencia y Mallorca en el siglo XV», Mayurqa, 26, pp. 181-193.

El corsario vasco, Sancho de Buitrón aparece en 1399, como responsable de la captura de dos barcas valencianas que volvían de Berbería y que se dirigían a Valencia con una carga de trigo (400 cahíces), cera, fideos, dátiles, nueces, dexac, algodón, cueros y otras mercancías que se necesitaban mucho en Valencia, particularmente el trigo. FERRER I MALlOL, M ${ }^{a}$. T. (2006). «Corsarios vascos en el Mediterráneo medieval (siglos XIV-XV)», Itsa Memoria. Revista de Estudios Marítimos del País Vasco, 5, Untzi Museoa-Museo Naval, San Sebastián, pp. 95-110.
} 
relevancia en el conjunto de estas importaciones, implicándose, en ellas, un destacado número de patrones, marineros y miembros de órdenes religiosas. De los hombres afincados en el puerto de salida y de llegada, algunos nombres podemos rescatar, como Juan Escrig que gestionará íntegramente 439 arrobas durante 1671, 1673, 1680, 1681 y 1684. También rescataremos al francés Benito Perrier que negociará, para él mismo, 438 arrobas durante el trienio 1671-1673 o el patrón Francés Zaragoza, en 1629, administrará 209 arrobas y en 1632 será el encargado de cursar 29 arrobas para el Convento de la Merced de Valencia.

Cerraremos este apartado, de origen vegetal, con un grupo de artículos, cuya relevancia, en este particular comercio, la podemos calificar de secundaria, la nómina de estos productos, se nutre de garbanzos, frutos secos, azúcar y especias.

En el apartado, reservado al comercio de pescados y salazones procedentes de Orán, la especie soberana, por el volumen tramitado, es la sardina; seguida del atún, dos ejemplares habituales en el mar Mediterráneo. Orán apenas interviene en el mercado atunero, apareciendo fugazmente en 1607 con 3 barselles tramitadas en su totalidad por el patrón Andrés Bramón y en 1627 con 2 barriles comprados por Vicente Ortola y Melchior Bou.

Por el contrario, el puerto oraní, tramitará en cuatro ocasiones, discretas partidas de sardinas, destacando la llevada a cabo por Tomás Toledo dirigida a Antonio Castell, que se eleva a medio millón de sardinas. Las otras dos son adquiridas en origen por Miquel Galón ( 5 barriles) para Vicente Ortola y Francisco Rodríguez le enviará 1 arroba a Vicente Campanar. El cuarto registro se asienta con el nombre de sardina irlandesa, concretamente 66 arrobas adquiridas y tramitadas por Nicolás Den Vila.

Orán, no estará ajena al comercio de animales vivos ${ }^{35}$, manifestándose su presencia por medio de la importación de quince carneros a partir de los años setenta, dilatándose hasta 1701. El año 1674 será el más dinámico, al anotarse cinco unidades tramitadas, en destino, por el patrón, Sebastián Pavía y destinadas a él mismo y a su sobrecargo. Los dos tercios restantes, pensamos que serían para consumo propio, de las personas que los gestionaron, como el caso del convento de la Merced, Nicolás Escoto, Jacazo Montero, Josep Cabrelles, Pau Goya o Vicente Andría. El resto de fauna apenas reviste importancia, a excepción de la remesa de

${ }^{35}$ La crónica-memorias de Diego Suárez Montañes nos acercan a la fauna de Orán, así podemos leer: Los animales domésticos de servicio del reino de Tremecén y demás reinos de Berbería son los mismos de la Europa: vacas y yeguas, cabras, ovejas, mulas y mulos, asnos y todo género de perros. Ibídem, p. 110. 
80 terneros y cabras que canalizo, en 1626, Pere Gonzalo. Completaremos este listado con los 6 terneros que, en 1664, compra Carlos del Mor, para su uso exclusivo; dos toros comprados y negociados por el patrón Agosti Sastre, y un asno transferido en 1600 por Gaspar Disso a Miguel Corvassi.

Los productos derivados de estos animales, entre otros, son la carne de cerdo, cabra y de carnero salado que llegará en modestas cantidades a Macia Cerda, Pedro Martegau y al dúo formado por Gregori Piquelques y Gasco. Le sigue la mantequilla que la encontraremos de forma aleatoria a lo largo de la centuria, con un total de 167 arrobas, señalando 1671 como el año donde se alcanzan, en una sola partida, las 146 arrobas compradas por Francisco Gauchi; de este restringido comercio rescataremos a los herederos de Escanio Sobregondi, mercader italiano afincado en Valencia, que administrarán 2 arrobas, para consumo propio. La cecina ( rescatar 1 sarria obtenida por Gaspar Zapa y 12 quintales por el patrón Pedro Martegau. También hemos verificado modestas anotaciones de morcillas, tocino y miel.

A lo largo del siglo XVII, como ponen de relieve las cifras del Peatge, en Valencia existió un dinámico mercado de pieles y cueros, del que se beneficiaba en primer lugar la propia industria local de preparación y transformación; recordemos que desde la Edad Media la ciudad del Turia fue uno de los grandes centros productores de manufacturas derivadas de las materias primas que estamos aludiendo, en donde blanquers y pelleters adobaban todo tipo de cueros y pieles de procedencia diversa. Sin duda parte de las importaciones tendrían un destino diferente, siendo reexportadas a otras ciudades del entorno mediterráneo próximo y al interior de la Península.

Orán, será uno de los puertos norteafricanos de donde se expedirán en diferentes periodos de la centuria importantes cargamentos de pieles, que segmentaremos en décadas para su mejor comprensión. El arranque del siglo lo tendremos que centrar entre 1603-1609, periodo del que subrayaremos 1603, el más activo al registrarse el mayor número de pieles, de diversa índole, que entran en el puerto-playa de Valencia; así hemos fiscalizado 1000 pieles de toro para López De Toto. Del mismo género se desembarcaron 750 piezas más, anotadas con el nombre de pieles de toro sin ningún otro calificativo, negociadas en su totalidad por Pedro Pons. Entre abril y mayo se adquirieron 200 pieles de cabrito con pelo, consignadas a Juan Genovart y Bertomeu Llauser. Las dos últimas partidas registradas hacen referencia a 35 pieles de becerro para Pedro Pons y 11 pieles adobades de blanquer adquiridas por Pedro Martegau. Los restantes años no alcanzarán el dinamismo mostrado en 1603, no obstante destacaremos las 880 pieles de toro con pelo 
suministradas a Cristófol Garcia y las 80 piezas de toro de India con pelo aportadas por el patrón Carlos Fenollo. En 1605, Juan Fiol, curtidor valenciano, importará 1018 pieles de toro con pelo y el patrón de origen francés Pierres Denanas y algunos de sus marineros servirán al mercado valenciano 40 pieles de carnero con pelo. El año 1606 destacará por alcanzar el techo, 1072 unidades, en las adquisiciones de pieles de toro con pelo, obtenidas por Cristófol García. El patrón Guillem Viguer, solo conseguirá 434 pieles de las mismas características. Por su parte Pedro Martínez y los marineros de la saetía patroneada por el aludido Guillem Viguer, serán los dueños de 84 pieles de carnero con lana. Pedro Martínez cerrará 1606 con 80 piezas de cabrito con pelo. El menos prolífico de todos será 1609 donde se anotarán 26 pieles de toro con piel, ajustadas en origen por el patrón Bertran Baneto, pasando posteriormente a manos de Francecs Nauri.

La cronología establecida nos llevará hasta 1615 con 3 balas de pieles de cabrito con piel, intermediando el patrón francés Jaques Esteve en nombre de Antonio Calvi. Los primeros años del trienio 1624, 1625 y 1629, se caracterizan por recibirse 180 pieles de jabali ${ }^{36}$ para los doctores Monflorit y Pellicer, por el contrario, 1629, se diferencia de los anteriores por el volumen y variedad de la mercancía. Se gestionaron 50 piezas de jabalí para el doctor Monflorit, 50 de carnero para Llacer del Mor y 381 de carnero con piel concertado por Jaume Arenós, Baltasar Palo y el doctor Monflorit.

Tras la década de los años veinte seremos testigos de un paréntesis comercial de estos artículos que se dilatará hasta 1645, donde seremos testigos de una momentánea mejoría al controlar 25 piezas de toro con piel, importadas por los marineros de la nao capitaneada por Enrique Ope y por la solitaria piel de toro solà de Vicente Postí. A partir de esta referencia volveremos a ser testigos de una nueva crisis que se alargará hasta el trienio 1654, 1658 y 1659; periodo que se caracterizará por la tipología de las pieles desembarcadas en el Grao valenciano, siendo testigos de la llegada (1654) de 500 pieles de macho con piel para el patrón Agostí Sastre. Cuatro años después levantaremos acta de la compra de 33 de jabalí para Pere Rabel; 31 de carnero, un fardo de pieles de vaca salvaje y dos de león para Francisco Alcalá. Cerrando 1659 con 145 piezas de toro de carnicería.

${ }^{36}$ El soldado asturiano, Diego Suárez Montañés, nos da una indirectamente una explicación a la gran cantidad de pieles de jabalí importadas desde Orán: [...] asimismo grandísimas manadas de jabalíes por todo el desierto de este reino, como lo habemos visto en varias partes de él porque, como los moros no comen tocino, no se curan de matarlos ni criarlo doméstico. AlONSO ACERO, B. (2006). «Trenes de avituallamiento...», p. 110. 
Una nueva interrupción temporal nos llevará hasta 1667, que se significa por la inclusión de 18 arrobas de piel de carnero y 1 fardo de diversas pieles para la pareja formada por Gregorio Piquelques/Riquelques y Miguel Gascó y Pere De la Torre respectivamente. Tres años después seremos testigos, en el cuatrienio 1670, 1671, 1672 y 1674, de cómo el patrón Jacamo Manito traslada una sarria de pieles de cabrito; de 2 balas y 5 fardos de piezas de jabalí para Oliver Esteve y Tomas Fort, de 120 unidades de macho y de cabra cuyo beneficiado será Benito Perder y, por último, el patrón Miquel Erell nos obsequiará con 250 pieles de jabalí.

Los años 1681 y 1684 se significarán por las transacciones realizadas por el patrón Juan San Andreu que participara en diferentes expediciones aportando 4 fardos de pieles de jabalí con piel y otros dos fardos más de macho con piel. Las restantes empresas las llevarán a cabo el patrón Josep Guardiola y Miguel Vidal que administrarán dos balas de pieles de jabalí y tres pieles de macho con piel.

El último movimiento se efectuará en 1700 al gestionar, Jerónima Cubeta (la única mujer que intervino en este comercio), 146 pieles de becerros pequeños.

\section{LA IMPORTACIÓN DE TEXTILES.}

Después de la alimentación, la segunda necesidad material humana esencial es la indumentaria, que es al mismo tiempo una necesidad física y una demostración de estatus social.

En el siglo XVII, los valencianos adquirían una gran parte de las materias primas imprescindibles para sus manufacturas fuera de sus fronteras. Las fibras textiles y las prendas transformadas a partir de ellas constituían una de las partes substanciales de este tráfico. La lista de tejidos con los que se especuló desde Orán fue discreta. Aunque presente en la importaciones de lana hacia Valencia, su volumen de negocio se reduce a 282 quintales y 1 saco, repartidos en 7 navíos, que llegarán al puerto-playa valenciano con agudas oscilaciones temporales (1603, $1625,1629,1645,1667$ y 16681). De los hombres que hacen posible este mercado, pocas conclusiones podemos extraer al desempeñar el doble papel de intermediarios y receptores. La repetición de nombres no se produce en ninguna ocasión, lo que nos lleva a recordar sólo a aquellos que su arqueo especulativo es mayor, como en el caso del patrón Pedro Marqués (116 quintales), el francés Pierres Bramon (68), Baltasar Palo (25) o Guillem Alegre (22).

Las prendas confeccionadas con lana, entran a formar parte de este entramado comercial; exhumándose un número representativo de atavíos como el alquícer o alquicel, las alfombras, las capuchas, los paños denominados estameñas, sayales o tapetes. 
Después de la lana hay que destacar el algodón, fundamentalmente las telas confeccionadas con esta fibra, que alcanzaron una notoria envergadura, al importarse una gama múltiple de prendas de variado uso como los albornoces (de diferentes colores), caliqui (ropa blanca de algodón), canicó (ropa elaborada con fibra de algodón que se utilizaba antiguamente para confeccionar prendas interiores), cofas, lienzos, anacotes, terliz, fustán, servilletas, toallas, turbantes y bayetas.

Al mismo tiempo que la lana y el algodón la industria valenciana se nutrirá de lino ("lli prim, lli en pel, lli filat") y seda, ambas en pequeñas cantidades, resultando anecdóticas en las exportaciones desde Orán. Otros productos que enriquece este comercio son los bocaram (telas de rayas procedentes de Pérsia), bocadells (paño delgado), trapos, filadís, jubones, jamelotes, barraganes, medias, tapins, talecas, fernandinas estrechas, tafetanes, velas, telas, sombreros y ropas.

\section{OTROS PRODUCTOS DE IMPORTACIÓN.}

Enlazados a la industria textil y a la manipulación de pieles y cueros concurren un grupo de artículos básicos en el finalizado de las piezas, especialmente para su blanqueo y coloración, las materias tintóreas; aunque su presencia en los cargazones oraníes es puntual, hemos rescatado de los registros consultados, algunas cantidades de gala, zumaque, alquena, índigo, grana, orchilla, el verdet o la cochinilla.

La cera, tuvo un intenso tráfico ya desde la Edad Media, como lo muestra su presencia en los registros aduaneros. Su uso no sólo era el de la iluminación particular en las casas, sino también tenía un fin social, ya que tenía múltiples aplicaciones en el ámbito eclesiástico. No sólo se utilizaba para confeccionar velas, cirios o antorchas, sino también en determinadas fases de la confección textil ${ }^{37}$

Su importación tuvo continuidad en los siglos de la modernidad, al no ceder su demanda y consumó; sino al aumentar su uso como consecuencia del incremento de la población. La importación desde Orán las dividiremos en dos espacios temporales desiguales en cuanto a las cantidades tramitadas; el periodo comprendido entre 1624-1639, Valencia recibirá 258 arrobas, una cantidad muy pobre si la comparamos con las 4535,5 arrobas del intervalo 1658-1701.

El polo Valencia-muelle oraní, abastecedor de cera, estarán unidos gracias a los esfuerzos de un conjunto de comerciantes y particulares que articularán unas

\footnotetext{
${ }^{37}$ Gual Camarena, M. (1968), Vocabulario del comercio Medieval. Colección de aranceles aduaneros de la Corona de Aragón (siglos XIII y XIV), Tarragona, p. 325.
} 
relaciones intermitentes, pero al mismo tiempo fluidas, entre los dos términos geográficos apuntados. Entre las numerosas referencias, destacaremos los nombres de Juan Escrig que desarrollara sus actividades comerciales durante los años setenta y ochenta, trasladando, 537 arrobas de cera, gestionada íntegramente por él, excepto en una ocasión en que 21 arrobas irán a parar a manos del Gobernador de Orán (25 de septiembre de 1681).

De los minerales que penetraron en esta centuria, en nuestra urbe, procedente de Orán, pocas conclusiones podemos extraer al tratarse de un comercio que podemos calificar de muy pobre; encontrándose partidas puntuales de materias primas como el hierro, el plomo, el acero, el azufre y el estaño. De los cuatro, el hierro consiguió las cuantías más destacas; encontrándolo en las nóminas de productos fiscalizados en el trienio 1672. 1679 y 1681. El volumen trasportado es muy desigual, así, el primer año se controlaron 56 arrobas, gestionadas en su totalidad por Juan Batiste Fábrega. En 1679, Vicente Datos adquirió 31 arrobas y el último año de la serie, Cipriano Moya negoció 1112 arrobas. El plomo, lo localizaremos en el bienio formado por los años 1679 y 1681; será contrato por Juan Bernardo Adorno (433 arrobas) y por Cipriano Moya (300 arrobas). Les sigue el acero al importarse un total de 254 arrobas, distribuidas en cuatro partidas de 172 y 10 arrobas en 1664, 22 arrobas en 1680 y de 50 arrobas en 1683, todas ellas formalizadas por Geroni Román, Manuel Botaso, Germán Selicofre y Antoni Causa El azufre ocupará el penúltimo lugar al contabilizarse 96 arrobas en 1691, siendo tramitado, por la pareja integrada por Pedro Jois y Juan Bey. El estaño se expedirá en el año 1681 gracias a las gestiones del Josep Guardiola (3 barriles) y Josep Bonilla (5 arrobas).

Los productos manufacturas no tiene una destacada presencia en estos intercambios, su adquisición es para uso particular, aunque puntualmente podemos encontrar algunos artículos que rompieron la dinámica general, como los clavos que los encontraremos en 1645, donde Alexandre Corner, agente en Orán de Miquel Corecha, le enviará 17 arrobas. En 1681, Josep Bonilla gestionará 115 arrobas. Les sigue els picots (martillo utilizado por los picapedreros), su importación se centra en el último cuarto del siglo $(1674,1681,1684,1695$ y 1701), su gestión tuvo la particularidad que en tonos los caso el remitente y el destinatario eran la misma persona, así hemos podido rescatar a los herederos de Josep Bonilla, a los patrones Juan Sant Andreu y Josep Cabrelles o al sacerdote Pere Arnau Escrig. El resto de artículos apenas revisten importancia, anotándose crisoles, campanas, ollas, paellas, quincalla, ruedas de plata falsa, tijeras d'abaxador, herraduras de caballo o agujas.

Las armas blancas y de fuego y accesorios no serán ajenas a estas transacciones, detectándose algunas partidas como las dos hojas de daga tramitadas por Domingo 
Beloto para Blai y Agustí Botaso y el cañón rayado que en 1629 trasladará, el patrón Juan de la Gos. Cerraremos este subcapítulo con una quarterola de pólvora tramitada por Juan Vinya en 1681.

La cerámica ocupa un lugar secundario en este complejo mercado, debido a que solo se adquieren piezas que se utilizan cotidianamente en la cocina o a la hora de preparar la mesa para cualquiera de las comidas diarias. Son objeto poco suntuosos de bajo coste y reemplazables con facilidad, si alguno se deteriora o se rompe. La adquisición de estas piezas se realizó con el fin de ser utilizadas por parte de las personas que las conseguían y la comercialización de ellas, en tiendas específicas. El volumen mercantilizado se limita a partidas pequeñas como las 8 tazas que encontraremos en el navío de Josep Román que las transportará hasta la playa valenciana donde las recogerá Antonni Melet. Este último mercader, en 1625, tramitará 14 cántaros pequeños para agua y 14 botijos, para su uso particular. Este apartado podemos darlo por concluido con las 6 cajas de búcaros oraníes que llegan en 1604 para Francisco Blandón de Mesquida.

Las plumas y plumeros ("plomalls y pelnajos") de diferentes clases (especialmente de avestruz) se muestran como un género relevante en los tráficos desde Orán. Núcleo de las expediciones que tuvieron lugar entre 1606 y 1670 (con sus lógicos paréntesis comerciales). Con el nombre genérico de plumas destacaremos el envio (1615) de 58 plumas de avestruz que llevará a cabo Mateu Pata para Ramón Marro. Le sigue Gregori Piquelque que a título individual o en compañía de Miguel Gascó aportó (en 1667) un total de 4 cajas. Los plumeros los encontraremos entre 1606 y 1626, diferenciándose del resto el asiento de 1.672 unidades que Joan de Arrensa comprará en origen para Jaume Segón; acompañado de las 184 unidades tramitadas por Pedro Martínez.

La evaluación importadora de tabaco la podemos calificar de modesta; el primer envio lo hemos detectando en 1635 y el último en 1687, con toda probabilidad serán el resultado de una serie de reexportaciones, como lo atestiguan los orígenes del tabaco relacionado en los registros (tabaco francés o brasileño ${ }^{38}$ ). El tabaco se trajo en rollos, que podían ser de dos tamaños, grandes o pequeños, y se vendían

${ }^{38}$ En relación al tabaco importado hasta Alicante José Ignacio Martínez Ruiz y Perry Gauci nos recuerdan que [...] se distinguen hasta cinco procedencias diferentes: Virginia, Barbados, St. Chistopher, Francia y Brasil. El más apreciado de todos era el de Brasil, pero debido al enfrentamiento entre Españ y Portugal, sólo se podía importar si llegaba a Alicante desde Inglaterra o Italia (habría que añadir las reexpediciones desde otros puertos, como en el caso que nos ocupa). Martínez Ruiz, J. I. y GaucI, P. (2008). Mercaderes ingleses en Alicante en el siglo XVII, Universidad de Alicante, Alicante, p. 52. 
por libras de 18 onzas. Los rollos menores se envolvían en papel, lo que garantizaba mejor su conservación y posibilitaba unos precios de venta más altos $^{39}$. También se comercializaba en polvo y sucio. Los resultados obtenidos, distinguiendo sus diferentes procedencias y formas, son: 49 arrobas de tabaco francés en rollo, en enero de 1681 (haciendo escala en Alicante) para Josep Bonilla. El brasileño, se tramita, 45 arrobas, en 1662 vía Alicante, destinadas a Campamar. Orán exportará todo el tabaco en polvo, en 1639 (20 libras), 1645 (40 libras) y 1671 (2 sarrias); asignadas a Manuel Cardós y Oliver Esteve. En los años 1639 y 1645 arribaron al Grao valenciano 251 arrobas y 3 sarrias de tabaco en rollo destinado a Antoni Fenollós y Julio Marineto.

El resto de mercancías no consiguen alcanzan la importancia de las anteriores, componiéndose su nómina de papel (de escribir y blanco), abanicos, bolsas, claveles, cuerdas, cristales, cuadros, goma, hilo de hierro, libros, barrilla o aguardiente.

Finalizaremos este recorrido comercial entre Orán y Valencia con los esclavos, un "artículo" más, que era tramitado, como eso, un producto al que se le tenía que sacar el máximo beneficio, sin importar si eran adultos o niños, si eran hombres o mujeres o si les unían lazos familiares. Lo importante es que eran un objeto que tenía que llegar al mercado en las mejores condiciones posibles, para sacarle el máximo rendimiento económico.

La esclavitud, en la modernidad, no era un fenómeno nuevo, ni tampoco una lejana evocación del mundo antiguo de las grandes propiedades esclavistas de la antigüedad romana, eclipsada con la caída del imperio y la cristianización de Europa $^{40}$. Nada más lejos de la realidad, considerables países cristianos perpetuaron esta práctica en las centurias medievales, en especial los bañados por las aguas mediterráneas. Herencia que se trasladará inalterable a los siglos que construyen la Edad Moderna. Las deportaciones masivas de personas de todas las edades y diferente sexo de origen africano hacia la península, serán habituales desde mediados del cuatrocientos encontrándolos, como una mercancía más, en los principales mercados ibéricos como Barcelona, Sevilla o Valencia.

Aunque nuestro trabajo abarca un periodo de 103 años (1600-1703), la realidad importadora se reduce a un periodo que se inicia en el arranque del siglo XVII (26

39 Ibidem, p. 52.

${ }^{40}$ Furió, A. (2002).«Mercancías humanas: el nuevo auge de la esclavitud al final de la Edad Media». En Manuel Chust, ed. De la cuestión señorial a la cuestión social (homenaje al profesor Enric Sebastià), Universidad de Valencia, Valencia, p. 23. 
de marzo de 1600) y finaliza, según las fuentes consultadas, el 23 de enero de 1683. Lapso temporal, donde hemos contabilizado 29 expediciones procedentes del espacio oraní. El número de personas privadas de su libertad que salieron de esta ciudad se eleva a 112. Los mercaderes afincados en esta ciudad, interpretaron, en la mayoría de las transacciones, el doble papel de remitentes y destinatarios; de la legión de personajes que hemos recuperado, destacaremos a Pedrós Batiste, comerciante del Grao, al que veremos desarrollando sus artes mercantiles en 1607 y 1614, años donde importó 12 esclavos, de ellos, 11 eran de su propiedad (4 niños de 2 y 3 años y el resto eran adultos de diferentes edades y sexo) y el que resta paso a manos del "tapiner" Nicolás Catalá. El patrón Pere Antich, al mando de su propia embarcación, suministro, en un sólo viaje, al mercado valenciano 11 esclavos en 1655. Gaspar Distre se relacionó con Joan Mario, el vecino de Vinaroz, al que le trajo en 1601 un total de 7 cautivos moros, 2 esclavas y 5 esclavos (de edades comprendidas entre los 9 y los 18 años). Honorat Gaçon expidió, en 1606, 7 mujeres musulmanas, al que suponemos de origen italiano, Joan Antonio Patrini Cessagoçolo. Otros negociantes afincados en ambas orillas fueron Francisco Rodrigo que trabajo para Pere Campaner y Francisco Rodrigo; Gaspar Disso para Miquel Corvassi o el dúo Juan Batiste Fabrega y Pedro Mateu que lo hicieron para ellos mismos.

$$
* * *
$$

Como hemos podido comprobar, con las matizaciones correspondientes, el comercio valenciano-oraní fue posible a lo largo del ciento tres años que transcurren entre 1600-1703. El caso valenciano fue muy similar, salvo algunos reflejos, a la mayoría de las ciudades españolas del litoral Mediterráneo, constatándose la existencia de un comercio dinámico, con sus altibajos, a lo largo del siglo XVII y principio del XVIII. 